\title{
Gear grinding system adapting to higher CNC grinder throughput
}

\author{
Vasily Larshin ${ }^{1, *}$, and Natalya Lishchenko ${ }^{2}$ \\ ${ }^{1}$ ONPU, Mechanical Engineering Department, 65044 Odessa, Ukraine \\ ${ }^{2}$ ONAFT, Department of Physics and Material Science, 65039 Odessa, Ukraine
}

\begin{abstract}
The paper is devoted to a solving an important scientific and technical problem of increasing the productivity of defect-free profile gear grinding on $\mathrm{CNC}$ machines on the basis of development of on-machine intelligent subsystems for the grinding operation designing, monitoring, and diagnosing which allow grinding system elements adapting to a higher productivity of the $\mathrm{CNC}$ grinder. The characteristic of the adaptation principle in manufacturing systems on $\mathrm{CNC}$ machines is given in accordance with both the systems and control theories. The productivity resources based on the use of the adaptation principle are studied and identified as well as a methodology is developed for researching the grinding system using scientific methods of modeling, optimization and control. Besides, corresponding technological preconditions are given in the form of a set of purposeful methods and means of innovative profile grinding technology, including grinding stock on-machine measurement and transformation the stock uncertainty into the grinding wheel displacement from the gear to be grinded.
\end{abstract}

\section{Introduction}

\subsection{Adaptation principle}

There are many ways to survive in the world competition and the adaptation principle use in technology is one of them just as it occurs in nature. For example, metalworking industry had to be adapted to a higher productivity with the product quality ensuring at the same time. This is a worldwide task to help manufacturers find new ways to increase productivity and profitability through more intelligent automation and best practice standards [1]. The adaptation principle in the mechanical engineering is gaining increasing recognition due to the success of its application in practice of automated production on CNC machines. This was the result of a natural process of computer-aided design of high technologies and the corresponding machining and grinding processes, including the gear grinding performed on the basis of CNC machine tools. One of the features of adaptive mechanical machining is its integration with on-machine process designing, monitoring (it is similar to measurement) and diagnosing (it is similar to control), which are performed on the same

\footnotetext{
* Corresponding author: vasilylarshin@gmail.com
} 
equipment, i.e. without the error of the workpiece setting and with eliminating the influence of the human factor. As a consequence, it is possible to significantly increase the process productivity, including profile gear grinding on CNC grinders. That is why the proposed work, which is the result of many years of experimental and theoretical research, is among the topical in mechanical engineering.

\subsection{Question status}

From the technological possibilities of existing gear grinding methods considered it was established that the most applicable are two methods of gear grinding, to wit the profile and worm ones. The first is now used instead of the former well known MAAG gear grinding method when the two dish grinding wheels worked without forced grinding lubricoolant. There were both high thermal intensity and very low productivity. The modern profile gear grinding is performed with the lubricoolant at the high pressure but has more large contact spot duration which is a reason of the higher grinding temperature. The analysis of the gear grinding labor-intensiveness during the gears production process has been made. As a result a significant amount of time spent on profile grinding operation (up to $40-70 \%$ ) is established. Therefore, the task of profile gear grinding productivity increasing on the CNC grinder under the high and dangerous grinding temperature is actual and important.

It is necessary to note that appearance of CNC gear grinders, in itself, allowed increasing the productivity of the grinding by means of ensuring the self-sufficiency, autonomy and mobility of the grinding system with CNC software and with the minimum participation of a machine operator in the implementation of all stages of the grinding operation. The profile gear grinding compared to the worm grinding ensures the higher accuracy of DIN 3-6, but yields less productivity. That is why, it is necessary to find reserves for further increase in productivity. The advantages of the profile grinding are simple kinematics of movements, a higher rigidity of the grinding system, and the possibility of grinding of any shape of the profile and with any gear modifications of the tooth in the range of both modules $0.5-35 \mathrm{~mm}$ and diameters - up to $8 \mathrm{~m}$.

It is known that the grinding stock for gear grinding determines the productivity of the operation because the stock is similar to a distance that should be overcome by a grinding wheel with the selected velocity named radial infeed. Therefore, studies related to the stock determination which based on the results of its selective on-machine measurement in certain selected tooth spaces are relevant as well. The possibility of obtaining information about the stock value and its actual location allows controlling the grinding wheel axial feed, denoted the $V_{f}$, by means of switching the feed from the working to the accelerated one in the absence of touching a grinding wheel and a gear.

The grinding stock measurement along the periphery of a gear on CNC machine allows to take into account the individual features of the gear when aligning the stock along the lateral sides of their tooth spaces, to ensure the individual removal of the stock taking into account its real both value and location along the periphery of the gear being grinded. However, the stock on-machine measurement consumes the auxiliary operation time, so there is a problem to reduce this time by optimizing the number of on-machine measurements. The feature of the grinding stock to be removed is its unplanned change along the gear periphery, which is influenced by the stock aligning chosen method for the further gear angular position correction. The causes of this stock change are the following: kinematic and geometric eccentricities, effect of previous heat treatment of gear to be grinded, etc. Proceeding from this, we can assume that the grinding stock contains both systematic and random components. That is why the theoretico-probabilistic approach was accepted to study the grinding stock. However, there are no focused studies of this assumption and the corresponding theory of determining the stock on the basis of stochastic 
model that correspond to the specified components of the stock. In addition, these models can be used for determining the value of retracting the grinding wheel from the gear to be grinded.

Along with modern $\mathrm{CNC}$ grinding machines there are these of obsolete models, which don't have the possibility of making corrections in the angular position of the gear without man' help. Therefore, to further increase the grinding operation productivity it is necessary to develop a method of aligning the stock without the gear angular position correction for additional loading of the obsolete grinders which will allow increasing the productivity of the grinding machines shop area. This issue has not been given due attention in the literature.

The gear grinding temperature is one of the factors limiting the productivity of the profile grinding operation. In the analysis of mathematical models of the temperature field during grinding, one of them should be used to determine the grinding temperature for a three-, two- and one-dimensional temperature field based, e.g., on the Fourier differential heat conduction equation. The analysis of the relevant works showed that there is no acceptable solution to define the grinding temperature for the purpose of operation designing, monitoring, and diagnosing. To substantiate this solution it is necessary to find conditions for the replacement of the complex thermophysical problem (two- and threedimensional) to the simpler one, e.g., one-dimensional solution, without a significant loss of accuracy in determining the gear grinding temperature. It has been shown that with a large grinding wheel axial feed $V_{f}$, when the Peclet number is more than 4 , the onedimensional solution mentioned above may be used.

The profile grinding is discontinuous because it contains the heating and cooling stages, which alternate from time to time. Therefore, it is necessary to develop a model for determining the temperature of the discontinuous grinding with forced lubricoolant. At the heating stage under the influence of the heat flux, the temperature increases, and at the cooling stage under the influence of the grinding lubricoolant the temperature decreases. On the basis of such a cycle, a model of the temperature of discontinuous grinding both at low frequency of heat flux pulses (macro-discontinuity) and high frequency (microdiscontinuity) can be obtained. This allows us to describe the grinding temperature in a wide range of both the heat flux pulses duty factor and frequency of the pulses including macrocycles of reciprocating displacements of a gear grinding wheel, macrocycles in the grinding by the wheels with artificial discontinuous surface, and even microcycles in the grinding with high-porous wheels. Such an approach has not been considered in the literature and is of interest in choosing grinding modes by the temperature criterion and for substantiating the characteristics of the profile grinding high-porous wheels. All of these researches help the gear grinding operation productivity increase.

To assess the grinding operation productivity a number of profile gear grinding characteristic values are used, among which common are: the specific material removal rate $Q^{\prime}{ }_{w}$ in $\mathrm{mm}^{3} /(\mathrm{s} \cdot \mathrm{mm})$ and the specific material removal $V_{w}^{\prime}$ in $\mathrm{mm}^{3} / \mathrm{mm}$. Each of them is reduced to a unit width of the grinding wheel profile. However, the literature does not describe the applied methods of determining the high-production grinding modes on the basis of these grinding operation indicators. There is no information on grinding designing, monitoring and diagnosing in real time. There is no mathematical dependence to determine the $Q^{\prime}{ }_{w}$ and $V^{\prime}{ }_{w}$ for an arbitrary curvilinear profile, which differs from the rectangular profile for traditional rectangular grinding schematics. It is a common opinion that the $Q^{\prime}{ }_{w}$ and $V^{\prime}{ }_{w}$ parameters predetermine the grinding temperature and grinding wheel wearing but the corresponding mathematical dependencies have not yet been installed. The analysis of literature has shown that the relationship between the $Q^{\prime}{ }_{w}$ parameter and the thermal burn is still a formal one, because it is unknown the relationship between the $Q^{\prime}{ }_{w}$ parameter and the 
grinding temperature $T$. Therefore, it is necessary to establish this relationship, i.e. to find the functions $T\left(Q_{w}^{\prime}\right)$ and $W\left(V_{w}^{\prime}\right)$, where $W\left(V_{w}^{\prime}\right)$ is the grinding wheel wearing.

The urgency of the operation designing, monitoring and diagnosing subsystems in gear grinding is due to the lack of deterministic relationships between the grinding system output parameters (gear accuracy and quality) and the input control (grinding modes) ones. The output parameters are determined after the end of the machining (the results control), when there is no possibility of correction of the results, which creates a problem to control the gear grinding operation. Therefore, the control of the relevant grinding system state parameters (grinding temperature, grinding wheel wear, etc.) could may the necessary corrections possible for obtaining the output parameters by means of input parameters regulation as well. However, the lack of both monitoring of these state parameters and the corresponding system of grinding diagnosing constrains the decision of the problem of increasing the profile gear grinding productivity.

\section{Grinding system information model}

There are many books on grinding which are dedicated to all those who are searching for a way to improve the productivity of man and machine. There are many investigations looking toward improvement of productivity within the manufacturing system [2, 3]. All of them need the grinding system scientific research methodology which includes the following sequential procedures: modeling, optimization and control [4]. These procedures characterize the grinding system to be investigated and controlled as a control object (Fig. 1), which has input parameters $\mathbf{u}$ (vector), state parameters $\mathbf{x}$ and output parameters $\mathbf{y}$.

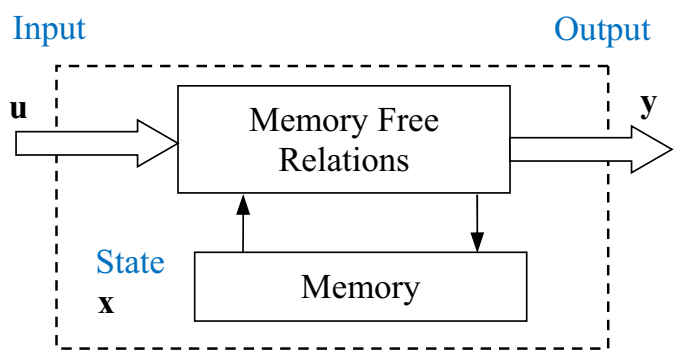

Fig. 1. Schematic of gear grinding system as a control object which has an input, a state and an output [5].

The interconnections between these parameters are not unambiguous and deterministic ones, therefore the task of the research is to identify these parameters, based on ensuring the least both the grinding stock measurement time and machining time. This requirement satisfies the representation of the grinding system in the form of an control object in which it is necessary to provide the output parameters required at the highest process efficiency with automated control of this object using the on-machine designing monitoring, and diagnosing subsystems [6, 7]. Operation monitoring and diagnosing of the state of the grinding system partly compensate for the lack of adaptive control of the output parameters, which is impossible due to the lack of information about the output parameters. At the same time, the grinding system diagnosing the state allows indirect characterization of its output parameters through deterministic-stochastic relationships, in which the information is distributed from the input parameters through the state parameters to the output ones. Unlike the output parameters, information about the state parameters can occur continuously providing the possibility of indirect adjustment of the output parameters and thus a solution of the problem. 


\section{The grinding stock measurements number optimization}

The theoretical preconditions for optimization of the profile grinding operation on a CNC machine are developed and tested, according to which the optimization is performed with the help of developed estimation functions. The one of them is the sum of squares of the difference of the grinding stock extreme values $\left(z^{L} \max , z^{R} \max , z^{L} \min , z^{R} \min\right.$; when $z^{L} \min =z^{R} \min$ as an angle position correction result), found by both the limited and maximum number of measurements, i.e., the latter case is the fiducial point to compare. The another one may be difference of the tooth space ordinal numbers with the maximum stock which are found for both the limited and maximum number of measurements, i.e., the latter case is again the fiducial point to compare (this function is not considered further). Thus, each of the dispersions $D_{1}\left(z^{L} \max \right), D_{2}\left(z^{R} \max \right)$, and $D_{3}\left(z^{R} \min \right)$, under the condition that $z^{L} \min =z^{R} \min$, represent the square of the difference of the corresponding stocks, found on the limited number of measurements, i.e., at $N<N_{\operatorname{MAX}}$ (compared option version) and the maximum number of measurements, i.e., at $N=N_{\text {MAX }}$ (base version or the fiducial point). The estimation function, which is the sum of dispersions, is determined as the following equation: $D_{0}=D_{1}\left(z^{L} \max \right)+D_{2}\left(z^{R} \max \right)+D_{3}\left(z^{R} \min \right)$. For example, the $D_{0}$ value can be defined for three gears (Gear1, Gear 2, and Gear 3 in Fig.2) each of them has 29 teeth. As it can be seen, the optimal number of measurements $N_{\text {opt }}$ of the grinding stock is equal to 9 out of 29 possible ones, i.e. $N_{\text {opt }}=9$.

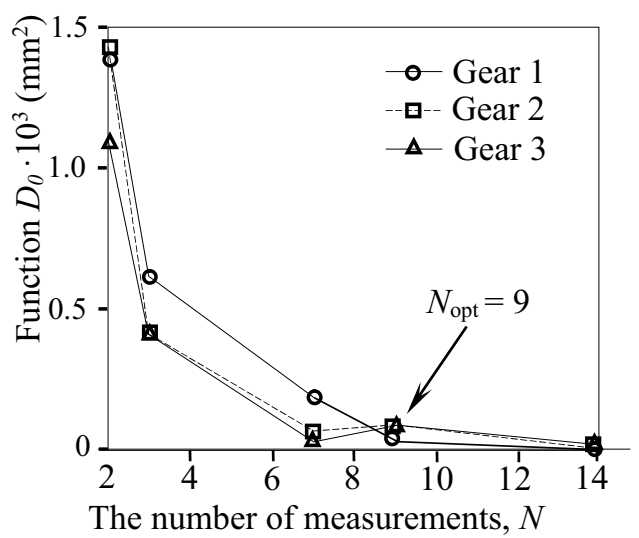

Fig. 2. Estimated function example for the three gears selected.

A nomogram based on the statistical data processing of twenty gears has been developed to select the number of measurements of the stock at the CNC gear grinder setting up stage is built when the grinder equipped with a Renishaw company's measuring tactile system (it may also be a measuring system based on acoustic emission signal control). Regression analysis has established a linear regression equation: $\hat{y}=0.368-0.005 N$, where $N$ is the number of the stock on-machine measurements. Confidence intervals $\pm t_{f, \alpha} S_{\hat{y}}$ and $\pm t_{f, \alpha} S_{e}$ to the regression line $\hat{y}$ depend on the following variables: $S_{\hat{y}}$ is standard deviation of regression value $\hat{y} ; S_{e}$ is standard deviation of forecast error; $t_{f, \alpha}$ is quantile of $t$-distribution with $f$ degrees of freedom at the significance $\alpha$ level. Let, for example, it is necessary to find the number of measurements of the stock on the gear with the number of teeth $N_{\mathrm{MAX}}=35$. The vertical is carried out on the nomogram to intersect with the lines of confidence intervals and the regression line. Then we determine the ordinates $N_{\text {opt }} / N_{\max }$ of all points: for point $7-0.072$; for point $8-0.167$; for point $9-0.211$; for point $10-0.254$; for point 
$11-0.349$. From here we find $N_{\mathrm{opt}}=\left(N_{\mathrm{opt}} / N_{\max }\right) \cdot N_{\max }$. We get: $N_{\mathrm{opt}}=2.52 ; 5.85 ; 7.37$; $8.90 ; 12.22$. Thus, the desired result with confidence intervals will be: $7.37 \pm 1.53$ and $7.37 \pm 4.85$ depending on the significance $\alpha$ level that we take.

\section{Gear grinding designing, monitoring and diagnosing subsystems}

In accordance with the equations derived (not shown here), a block diagram of computer subsystem for on-machine gear grinding operation designing, monitoring and diagnosing is developed, which differs from the existing monitoring system on the CNC grinders by the possibility of determining both the specific grinding work $A^{\prime}$ in $\mathrm{J} / \mathrm{mm}^{3}$ and the gear grinding temperature $T$ in ${ }^{\circ} \mathrm{C}$. Input parameters for the gear grinding system unit are the following: the part drawing data, $a$ is the material thermal diffusivity in $\mathrm{m}^{2} / \mathrm{s}, \lambda$ material thermal conductivity in $\mathrm{W} /\left(\mathrm{m} \cdot{ }^{\circ} \mathrm{C}\right), \psi$ share of heat flow transferred into the gear in grinding. Input parameters for the calculating device unit: $t_{v}$ is the grinding depth in $\mathrm{mm}, V_{f}$ is axial feed in $\mathrm{mm} / \mathrm{min}, B$ grinding wheel width in $\mathrm{mm}, z^{L}(n)$ and $z^{R}(n)$ are the left and right grinding stocks in $\mathrm{mm}$ ( $n$ is the current tooth number), $A E$ is signal of acoustic emission in relative units, and $P$ is grinding power in $\mathrm{W}$.

\section{References}

1. OMAC - The organization for machine automation and control, http://omac.org/news [Date accessed 15/08/18].

2. Robert I. King, Robert S. Hahn, Handbook of modern grinding technology (New York, London, 1986)

3. V.P. Larshin, N.V. Lishchenko, In: XVIIth Int. Sc. and Tech. Conf. "The Progressive Techniques, Technology and Engineering Education", 307 (2017)

4. V.P. Larshin, N.V. Lischenko, STIN, 3, 14 (2018)

5. Herbert Freeman, Discrete-time systems: an introduction to the theory (J. Wiley, New York, 1965)

6. H.K. Tönshoff, T. Friemuth, J.C. Becker, CIRP Annals, Manufacturing Technology, 51, 2, 551 (2002)

7. Fritz Klocke, Manufacturing Processes 2: Grinding, Honing, Lapping (Springer, Berlin, 2009) 